\title{
A computational approach for molecular characterization of Covaxin (BBV152) and its ingredients for assessing its efficacy against COVID-19
}

\author{
Atala B Jena \\ Utkal University https://orcid.org/0000-0002-1690-7913 \\ Asim K. Duttaroy ( $\square$ a.k.duttaroy@medisin.uio.no) \\ University of Oslo https://orcid.org/0000-0003-1619-3778
}

\section{Research Article}

Keywords: SARS-CoV-2, Coronavirus, Covaxin, ACE2, HSA, Drug-protein interaction, 2-Phenoxyethanol, and imidazoquinolinone

Posted Date: February 8th, 2022

DOI: https://doi.org/10.21203/rs.3.rs-1332649/v1

License: (c) (i) This work is licensed under a Creative Commons Attribution 4.0 International License.

Read Full License 


\section{Abstract}

SARS- CoV-2 vaccination is a life-saving strategy for the entire population living in this pandemic. A dozen vaccines against SARS- CoV-2 were developed and approved for the combat of the COVID-19 pandemic. However, there are many concerns on all vaccines, particularly on the immunogenicity and reactogenicity of vaccines, such as Covaxin. Covaxin (a vaccine code-named BV152), an inactivated COVID-19 vaccine. To address the concern outlined above, we explored the molecular and protein interactions between S protein, angiotensin-converting enzyme 2 (ACE2), and human serum albumin (HSA) with the ingredients of covaxin along with its drug-likeness property. The Autodock Vina shows stronger interactions of 2-phenoxyethanol, imidazoquinolinone (covaxin ingredients) with virus-cell surface $S$ protein, human cell membrane receptor ACE2, and plasma albumin. The molecular and proteinprotein interactions of S protein with ACE2 in the presence of 2-phenoxyethanol and imidazoquinolinone may affect the $S$ protein function by reducing the binding energy between these proteins. Covaxin vaccine showed excellent efficacy in averting the virus and may result in herd immunity. As reported here, imidazoquinolinone, used as an ingredient of covaxin, may have the drug-likeness property based on pharmacokinetic and physicochemical parameters. However, the results should be interpreted with caution as there are limitations such as immune response and adverse effects after vaccination.

\section{Introduction}

The prevention of severe acute respiratory syndrome coronavirus 2 (SARS-CoV-2) pandemic disease remains a major international public health priority due to the high infection rate and associated mortality worldwide. COVID19 creates the most significant catastrophe event in humankind in 2020. Despite the use of masks, sanitization, and antiviral drugs, there is a need to develop a vaccine against COVID-19. At the beginning of this year, several vaccines were developed and approved worldwide for the prevention of COVID-19. Several vaccines, including those manufactured by Pfizer, Oxford-AstraZeneca, Covisheild, and Covaxin, have shown superior protection to COVID-19. All these vaccines are approved by the World health organization for human use. The Covaxin (code named as BV152), an inactivated COVID-19 vaccine, was developed and assessed by the Bharat Biotech, India also. The Covaxine showed promising efficacy and immunogenicity towards SARS-CoV-2. The covaxin vaccine is available in a double dose. The manufacturer developed a formulation containing the whole virion inactivated SARS-CoV-2 antigen (strain: NIV-2020-770), adjuvant aluminum hydroxide gel, immunostimulatory imidazoquinolinone, and the preservative 2-phenoxyethanol (2-PE).

SARS-CoV-2 comprises a genome size of $~ 30$ kilobases of different structural and accessory proteins [1, 2]. In coronavirus morphology, there are four structural proteins: membrane (M) protein, spike (S) protein, nucleocapsid ( $\mathrm{N}$ ) protein, and envelope (E) protein [3]. The S protein consists of $\mathrm{N}$ exo and $\mathrm{C}$ endo terminals. The $\mathrm{S} 1$ subunit of the $\mathrm{N}$ terminal contains the Receptor Binding Domain (RBD), and the S2 subunit induces membrane fusion. The binding of S1 and S2 subunits causes fusion in the cell membrane, which induces viral invasion into the human cell by attaching to the Angiotensin-Converting Enzyme 2 (ACE2), [4, 5] the coronavirus receptor, can be a specific target to avert viral entry [6]. 
The above concerns can be understood by a cost-effective and reliable method using computational approaches. The molecular and protein interactions, ligand-based binding affinities for molecules, and drug docking studies can be carried out using available various bioinformatics tools. In order to understand these complex interactions, we have employed computational approaches to study the interaction between the components of covaxin (2-phenoxyethanol and imidazoquinolinone) with HSA, ACE2, and S protein.

Human serum albumin (HSA), a plasma protein, carried various biological molecules to transport several tissues in the circulation. HSA comprises three structural domains, and 17 disulfide bonds protect from aggregation, adsorption, and vaccine ingredients and improve solubility and low immunogenicity. Its physiological functions include maintaining osmotic pressure, anti-inflammation, and transport of plasma molecules $[7,8]$. However, the SARS-CoV-2 inhibits the albumin transport by inhibiting the endothelial glycocalyx formation. Therefore, HSA makes it of great interest to investigate how covaxin interacts with imidazoquinolinone, and 2-phenoxyethanol (2-PE), which might modulate the symptoms of COVID-19.

Phenoxyethanol, or 2-phenoxyethanol, is used as a preservative and works against bacteria by decoupling oxidative phosphorylation from respiration and competitively inhibiting malate dehydrogenase. Considering its broad antimicrobial characteristics, this is a highly effective vaccine preservative $[9,10]$. However, there are concerns regarding the formulation, safety, tolerability, and immunogenicity of covaxin despite its efficacy. The exact explanation for its efficacy, molecular and structural interaction such as DNA-protein, protein-protein interactions, and structural moieties is unclear.

This study assesses the vaccine covaxin safety, immunogenicity, hesitance, and resistance against the SARS- CoV-2 using a new methodology. We believe that this methodology will help develop future vaccines and other targeted therapies.

\section{Materials And Methods}

\section{Sequence analysis}

We have retrieved cryo-EM structures of COVID-19 S protein (PDB ID-6vsb), X-Ray crystal structures of ACE2 (PDB ID-1 r42), and HSA (PDB ID-1e78) from the PDB database at resolutions of $3.46 \AA$, $2.2 \AA$, and $2.6 \AA$, respectively, which are used for the computational study. Before molecular interaction analysis, the FASTA sequence of the above PDB structures was used to analyze its physicochemical property and secondary structure prediction in ExPASyProtParam and SOPMA programs, respectively.

\section{Investigation of S-protein- ACE2 interaction in the presence of 2-Phenoxyethanol and imidazoquinolinone}

A computerized rigid-body docking tool, clusPro 2.0, was used for S protein-ACE2 protein-protein docking analysis in the presence or absence of 2-Phenoxyethanol and imidazoquinolinone.This program aids in the screening of docked conformations for clustering features based on various protein parameters. The 
filtered conformations were selected based on empirical estimation of free energy. Free energy was calculated by taking desolvation and electrostatic energies into account. ClusPro is accessible at https://cluspro.bu.edu/publications.php. ClusPro clustering program detects native sites with the help of Piper's rigid docking tool based on FFT [11]. The native site is assumed to possess a wide range of free-energies to draw a more significant number of results. Initially, the sample was taken for about $10^{9}$ positions of the ligand for the receptor. Only the top $10^{3}$ positions were selected among all relative ligand positions corresponding to the receptor.

\section{Molecular docking analysis between ACE2, HSA, and S protein with 2-Phenoxyethanol and imidazoquinolinone}

The binding affinities of HSA, ACE2, and S protein with 2-Phenoxyethanol and imidazoquinolinone were evaluated through molecular docking program AutoDock Tools 1.5.6. The canonical SMILES ids of 2Phenoxyethanol are acquired from the PubChem database (https://pubchem.ncbi.nlm.nih.gov/). Imidazoquinolinone molecule is not available in the PubChem database. However, it is structured by using ACD/ChemSketch. CHIMERA 1.11.2 [12] program used for the conversion into 3D structures. The binding affinity of HSA, ACE2 and S protein with 2-Phenoxyethanol and imidazoquinolinone was estimated using AutoDock Vina1.1.2 [13]. The binding sites of the above receptors are used to recognize various parameters such as binding affinity, receptor pocket atom, receptor-interacting atom, atomic contact energy (ACE), receptor-ligand interaction site, and side amino acid residues. Discovery Studio 2017 R2 was analyzed by Client Pictorial depiction of docking results (Dassault Systemes BIOVIA, 2016).

\section{Drug likeliness analysis}

Swiss ADME is a comprehensive web-based tool that links physicochemical, pharmacokinetic, and molecular medical chemistry drug-likeliness to determine proficiency. Bioavailability Radar (solubility, size, polarity, lipophilicity, saturation, and flexibility) has been used to determine drug-likeness. For drug development, the analysis of ADME (abstraction, distribution, metabolism, and excretion) is vital. The 2Phenoxyethanol Canonical SMILES id was retrieved from the PubChem database and predicted ADME properties in Swiss ADME (http://www.swissadme.ch/) was carried out. Similarly, the structure of imidazoquinolinone has been used for ADME prediction. Using the Swiss Target Prediction tool, these two molecules are predicted as effective bioactive macromolecular targets in Homo sapiens.

\section{Results And Discussion}

\section{Molecular interactions study}

Covaxin is demonstrated to produce antibodies and show a robust response against the COVID-19 virus [16]. It is approved in thirteen countries and shows minimal to no adverse events (https://covid19.trackvaccines.org/vaccines/approved/). However, there are some concerns about tolerability, molecular interactions, and safety. These issues were addressed here using the computational biology approach. The binding and interactions activity of HSA, ACE2, S Protein, and ingredients of the 
Covaxin were studied. The molecular interaction study provides the binding affinity of 2-phenoxyethanol, Imidazoquinolinone, S protein, ACE2, and HSA.

The molecular interaction study provided the binding affinity of 2-phenoxyethanol, Imidazoquinolinone, S protein, ACE2, and HSA. Analysis of the binding interactions of 2-Phenoxyethanol, imidazoquinolinone with virus-cell surface protein S protein, human cell membrane receptor ACE2 and drug carrier protein HSA was carried out using the Autodock Vina 1.1.2. The binding energies of the molecular interaction study were determined as $\Delta \mathrm{Gb}-5.3 \mathrm{Kcal} / \mathrm{mol}$ and $\Delta \mathrm{Gb}-8.5 \mathrm{Kcal} / \mathrm{mol}$ when ACE2 interacts with 2Phenoxyethanol and imidazoquinolinone, respectively (Figure 1, Figure 2). In contrast, $\Delta \mathrm{Gb}-5.3 \mathrm{Kcal} / \mathrm{mol}$ and $\Delta \mathrm{Gb}-9.1 \mathrm{Kcal} / \mathrm{mol}$ were the energies, respectively, when HSA interacts with 2-Phenoxyethanol, Imidazoquinolinone (Figure. 3, Figure 4). On the contrary, the binding affinities scored to be $\Delta \mathrm{Gb}-5.2$ $\mathrm{Kcal} / \mathrm{mol}$ and $\Delta \mathrm{Gb}-8.5 \mathrm{Kcal} / \mathrm{mol}$ when $\mathrm{S}$ protein interacts with the above molecules (Figure 5, Figure 6).

The imidazoquinolinone bound S protein through multiple bonds and interactions, including Vander Waal's (Asn317, Ser316, Thr315, Thr761, Thr302, Tyr313, Thr768, Gln314, Asn764, Thr739); Conventional hydrogen bond (Thr302) Pi-Anion (Asp-737) Pi-alkyl (Cys760, Leu303) Alkyl (Arg765) (Figure 6). Imidazoquinolinone engage with ACE2 with Vander Waal's (Ala348, Thr347, Glu402, His401, Trp69); Conventional hydrogen bond (Tyr385); Pi-Pi T-shaped (His378); Pi-Pi stacked (Phe390, Phe40); Pi-alkyl (Arg393); Salt bridge (Asp350, Asp382) (Figure 2). Furthermore, imidazoquinolinone engages with HSA by Van der Waal's (Met123, Phe134, Glu141, Tyr138, Phe157, Gly189, His146, Leu115); Conventional hydrogen bond (Tyr161, Leu185); Pi-sigma (lle142); Pi-alkyl (Arg186, Lys190); Alkyl (Lys137) (Figure 4).

Similarly, 2-Phenoxyethanol bind with S protein of coronavirus by Van der Waal's (GIn564, Phe565, Val576, Phe543, Leu517, Cys391, Ala522, Leu518, Pro521); Carbon hydrogen bond (Asn544) Conventional Hydrogen Bond (Asn544); Pi-Alkyl (Leu546) (Figure 5), with ACE2 by Van der Waal's (Leu91, Asn210, Lys562, Ala396, Glu564); Carbon hydrogen bond (Pro565); Unfavourable donor (Trp566); Pi-alkyl (Val212, Val209); Pi-sigma (Leu95) and HSA by Van der Waal's (Asn391, Ala449, Leu387, Val433, Phe403, Tyr411); Conventional hydrogen bond (Cys392, Ile388); Pi-sigma (Leu453); Pi-alkyl (Leu430, Leu407) (Figure 1, Figure 3).

From the above molecular interaction data, it was observed that 2-Phenoxyethanol binds with RBD (Receptor Binding Domain) of S protein which spans from 319 amino acids to 591 amino acid residues in $S$ protein [17]. Similarly, imidazoquinolinone strongly interacts with S protein compared to 2-

Phenoxyethanol with the proximity of the RBD site. Both compound form hydrogen bonds with S protein which, play an essential role in molecular interaction [18]. The binding affinity and position of the above two compounds suggest that these molecules may cause hindering in S Protein function, which was also reflected in the protein-protein interaction study.

Imidazoquinolinone strongly interacts with the IB domain (Span from 108-196) of HSA with a binding affinity $\Delta \mathrm{Gb}-9.1 \mathrm{Kcal} / \mathrm{mol}$, which plays a vital role in drug delivery $[7,8]$. Similarly, 2-Phenoxyethanol binds with IIIA domain (Span from 384-497) of HSA with a binding affinity $\Delta \mathrm{Gb}-5.3 \mathrm{Kcal} / \mathrm{mol}$, an effective drug binding site [19]. 
The evidence above showed that Covaxin (2-Phenoxyethanol, imidazoquinolinone) ingredients show a robust binding affinity towards ACE2 and S protein HSA (Table 1). Imidazoquinolinone showed the highest affinity with $S$ protein, ACE2, and HSA with energies $\Delta \mathrm{Gb}-8.5 \mathrm{Kcal} / \mathrm{mol}, \Delta \mathrm{Gb}-8.5 \mathrm{Kcal} / \mathrm{mol}$, and $\Delta \mathrm{Gb}-9.1 \mathrm{Kcal} / \mathrm{mol}$, respectively.

\section{Protein-protein interaction study}

There are 10 top docking models listed on the ClusPro web server with various free energies. A grouping criterion was used based on the overall RMSD [15]. Our study analyzed 5 ClusPro docking models chosen based on S Protein probability, S Protein with 2-Phenoxyethanol, and imidazoquinolinone to engage with the anticipated binding sites ACE2 as well as the lowest binding energy during such interactions. For the $S$ Protein-ACE2 interaction, the average binding energy for all 5 binding sites is $-901.2 \mathrm{~kJ} / \mathrm{mol}$.

Nevertheless, the average binding energy for S Protein-ACE2 in the presence of 2-Phenoxyethanol is $-696.64 \mathrm{~kJ} / \mathrm{mol}$, and imidazoquinolinone is $-589.46 \mathrm{~kJ} / \mathrm{mol}$ (Figure 7, Figure 8 and Figure 9; Table 2).

Protein-protein interactions are highly specific physical contacts created by electrostatic forces, hydrogen bonding, and hydrophobic interactions between two or more protein molecules [20,21]. An analysis of protein-protein interactions can provide important information about the molecular networks that comprise a living cell [22]. Furthermore, the interaction of protein-protein plays a significant role in predicting the protein activity of molecules that target protein and drug ability [23]. In the presence of 2Phenoxyethanol, imidazoquinolinone, the binding energy of S protein, ACE2, was reduced during proteinprotein interaction. In comparison to direct binding, S protein interaction with ACE2 in 2-phenoxyethanol resulted in a substantial decrease in the binding energy of $204.56 \mathrm{~kJ} / \mathrm{mol}$ and $311.74 \mathrm{~kJ} / \mathrm{mol}$ in the presence of Imidazoquinolinone (Figure 7, Figure 8, and Figure 9). As a result, it's possible that 2phenoxyethanol, or imidazoquinolinone, can prevent the RBD site of S protein from attaching to the ACE2 receptor protein.

\section{Drug likeliness analysis}

We investigated the drug-likeness of the lead compounds, which are 2-phenoxyethanol and imidazoquinolinone, using the SwissADME tool. It determined the connection between the molecule's pharmacokinetics and physicochemical properties. The physicochemical properties of 2-Phenoxyethanol $\left(\mathrm{C}_{8} \mathrm{H}_{10} \mathrm{O}_{2}\right)$ were determined, i.e., $138.16 \mathrm{~g} / \mathrm{mol}$ molecular weight, molar refractivity of $38.90,10$ heavy atoms, 3 rotatable bonds, 2 hydrogen bond acceptors, 1 hydrogen bond donor, and topological polar surface area of $29.46 \AA^{2}$. Similarly, physicochemical properties for Imidazoquinolinone $\left(C_{19} \mathrm{H}_{21} \mathrm{~N}_{5} \mathrm{O}\right)$ were determined, i.e.,335.40 g/mol molecular weight, molar refractivity of 100.12, 25 heavy atoms, 2 rotatable bonds, 3 hydrogen bond acceptors, 1 hydrogen bond donor, and topological polar surface area of 66.81 $\AA^{2}$. The average lipophilicity score of 2-Phenoxyethanol iLOGP, XLOGP3, WLOGP, MLOGP, and SILICOS-IT models computes to 1.35. The bioavailability Score of the molecule is 0.55 . It has been noted that 2Phenoxyethanol has very solubility in water. SwissADME uses five distinct criteria to predict drug-likeness (Lipinski, Ghose, Veber, Egan, Muegge). Lipinski, Veber, and Egan obey the drug-likeness property of 2- 
Phenoxyethanol, whereas Ghose and Muegge are not. Similarly, for lipophilicity score of Imidazoquinolinone iLOGP, XLOGP3, WLOGP, MLOGP, and SILICOS-IT models compute to 2.27. The bioavailability Score of the molecule is 0.55 . It is observed that Imidazoquinolinoneis soluble in water. All 5 models render Imidazoquinolinonecompetent for an adequate drug molecule (Table ST1, ST2). The BOILED-Egg model assumes that 2-phenoxyethanol and imidazoquinolinone can easily pass through the blood-brain barrier and be absorbed by human gastrointestinal absorption (HIA) [23]. Based on the model, the parameters such as lipophilicity, solubility, drug-likeness, and pharmacokinetics that imidazoquinolinone could be a potential drug candidate. The 2-phenoxyethanol's pharmacokinetics and drug-likeness properties have sparked debate about whether it should be considered a drug molecule. Swiss Target prediction, a webserver, plays a central, critical role in identifying ligand-target of known molecules $[20,25,26]$. It accurately predicts the targets to modulate their behavior, elucidating the molecular mechanism and predicting cross-reactivity in 2D and 3D similarity events with known ligands $[27,28]$. It also detects potential side effects and assists in the repurposing of molecules for new uses $[25,29]$. Using the SwissTarget method, 2-phenoxyethanol shows a high predictive performance level of interaction with A G and C G coupled receptors, kinases, enzymes, and nuclear receptors. The major druglikeness targets from this prediction are A G coupled receptors and enzymes. In addition (Fig. SF4), imidazoquinolinone shows a variety of $A G$ and $B G$ coupled receptors, enzymes, and histone-modifying enzymes without affecting the vaccine ingredients' function (Fig. SF3).

Molecular interaction data suggested that imidazoquinolinone had a robust binding affinity compared to 2-Phenoxyethanol, corroborating the protein-protein interaction data. Imidazoquinolinone hinders maximally the S Protein ACE2 interaction as compared to 2-phenoxyethanol. Molecular interaction data also suggest that imidazoquinolinone binds to the RBD site of S Protein which may cause hindering in $S$ Protein-ACE2 complex formation. Protein-protein interactions regulate various biological functions, including cell to cell interactions, metabolic regulation, and developmental control [24]. This could open the door to repurposing/designing appropriate treatment to deter viral penetration using 2Phenoxyethanol and imidazoquinolinone in vaccine covaxin. A molecule must achieve the target in optimum concentration and be usable in the bioactive form before the necessary biological events arise for it to be an effective drug. The SwissADME technology reduces the time and resources required for drug development. To be considered an oral drug candidate, development products' structural or physicochemical properties must be evaluated for drug-likeness. A molecule's drug-likeness is determined for bioavailability by qualitatively assessing the likelihood of the molecule is to be formed into an oral drug. Bioavailability Radar defines the optimal set of properties like lipophilicity, saturation, scale, polarity, size, and flexibility for the input molecule drug-likeness of 2-phenoxyethanol and Imidazoquinolinone (Fig. SF1, SF2). Most protein targets are predicted using experimentally defined vaccine adjuvants and molecular similarities, according to the study. These adjuvants are effective against virus entry but less effective against biological targets in humans.

\section{Conclusions}


This approach delivers satisfying results in molecular interaction, protein-protein interactions, and druglikeness activities based on the data obtained. It is reasonable to deduce that Covaxiningredients(2phenoxyethanol, imidazoquinolinone) show strong binding affinity towards ACE2 and S protein and HSA. The molecular and protein interaction of its binding affinity and position of the above two compounds may affect the $S$ Protein function and reduce the binding energy between S Protein and ACE2. The Boiled egg model also proves the compelling drug-likeness property of these compounds in the blood-barrier system. These findings provide a necessary implication that the utilization of 2-Phenoxyethanol and imidazoquinolinone in covaxin in repurposing/design effective therapy to prevent viral entry; however, the approach is successfully demonstrated, a significant limitation in assessing the metabolites involved before and after vaccination using principal variance component analysis by $\mathrm{R}$ tool and identifying genes involved blood-barrier system using omics data to show the adverse and immune responses against vaccine in terms of age, race, ethical background, and other parameters. Since several issues remain unaddressed, a future extension is initiated to give a comprehensive understanding of system vaccinology to predict covaxin vaccine immunogenicity and reactogenicity.

\section{Declarations}

\section{Acknowledgments}

We gratefully acknowledge the great encouragement and support of R\&D Centre, BJB (A) College, Bhubaneswar, for their help and encouragement in preparing the manuscript. Authors are also thankful to the World Bank-Odisha Higher Education Program for Excellence and Equity (World Bank-OHEPEE), Government of Odisha for supporting Centre of Excellence in Integrated in Omics and Computational Biology, Utkal University.

\section{Conflict of interests}

The authors declare no competing financial interest.

\section{Ethical approval}

This research did not require statements of ethical consent or standards of animal care since the study did not use any human or animal subjects.

\section{References}

1. Gu W, Zhou T, Ma J, Sun X, Lu Z (2004) Analysis of synonymous codon usage in SARS Coronavirus and other viruses in the Nidovirales. Virus Res 101:155-161.

https://doi.org/10.1016/j.virusres.2004.01.006

2. Ahmed SF, Quadeer AA, McKay MR (2020) Preliminary Identification of Potential Vaccine Targets for the COVID-19 Coronavirus (SARS-CoV-2) Based on SARS-CoV Immunological Studies. Viruses 12. https://doi.org/10.3390/v12030254 
3. Bosch BJ, van der Zee R, de Haan CAM, Rottier PJM (2003) The coronavirus spike protein is a class I virus fusion protein: structural and functional characterization of the fusion core complex. J Virol 77:8801-8811. https://doi.org/10.1128/jvi.77.16.8801-8811.2003

4. Walls AC, Tortorici MA, Frenz B, Snijder J, Li W, Rey FA, DiMaio F, Bosch BJ, Veesler D (2016) Glycan shield and epitope masking of a coronavirus spike protein observed by cryo-electron microscopy. Nat Struct Mol Biol 23:899-905. https://doi.org/10.1038/nsmb.3293

5. Millet JK, Whittaker GR (2015) Host cell proteases: Critical determinants of coronavirus tropism and pathogenesis. Virus Res 202:120-134. https://doi.org/10.1016/j.virusres.2014.11.021

6. Wu C, Liu Y, Yang Y, Zhang P, Zhong W, Wang Y, Wang Q, Xu Y, Li M, Li X, Zheng M (2020) Analysis of therapeutic targets for SARS-CoV-2 and discovery of potential drugs by computational methods. Acta Pharm Sin B 10:766-788. https://doi.org/10.1016/j.apsb.2020.02.008

7. Guizado TRC, Louro SRW, Pascutti PG, Anteneodo C (2010) Solvation of anionic water-soluble porphyrins: A computational study. Int J Quantum Chem 110:2094-2100. https://doi.org/10.1002/qua.22700

8. Guizado TRC, Louro SRW, Anteneodo C (2011) Hydration of hydrophobic biological porphyrins. J Chem Phys 134:055103. https://doi.org/10.1063/1.3544376

9. Dréno B, Zuberbier T, Gelmetti C, Gontijo G, Marinovich M (2019) Safety review of phenoxyethanol when used as a preservative in cosmetics. J Eur Acad Dermatol Venereol 33:15-24. https://doi.org/10.1111/jdv.15944

10. Hua D, Xu P (2011) Recent advances in biotechnological production of 2-phenylethanol. Biotechnol Adv 29:654-660. https://doi.org/10.1016/j.biotechadv.2011.05.001

11. Kozakov D, Hall DR, Xia B, Porter KA, Padhorny D, Yueh C, Beglov D, Vajda S (2017) The ClusPro web server for protein-protein docking. Nat Protoc 12:255-278. https://doi.org/10.1038/nprot.2016.169

12. Pettersen EF, Goddard TD, Huang CC, Couch GS, Greenblatt DM, Meng EC, Ferrin TE (2004) UCSF Chimera-a visualization system for exploratory research and analysis. J Comput Chem 25:16051612. https://doi.org/10.1002/jcc.20084

13. Trott O, Olson AJ (2010) AutoDock Vina: improving the speed and accuracy of docking with a new scoring function, efficient optimization, and multithreading. J Comput Chem 31:455-461. https://doi.org/10.1002/jcc.21334

14. Dassault Systemes BIOVIA. BIOVIA Discovery Studio - BIOVIA - Dassault Systèmes ${ }^{\circledR}$. Published 2017. Accessed September 29, 2021.

15. Pi M, Kapoor K, Ye R, Nishimoto SK, Smith JC, Baudry J, Quarles LD (2016) Evidence for Osteocalcin Binding and Activation of GPRC6A in $\beta$-Cells. Endocrinology 157:1866-1880. https://doi.org/10.1210/en.2015-2010

16. Kyriakidis NC, López-Cortés A, González EV, Grimaldos AB, Prado EO (2021) SARS-CoV-2 vaccines strategies: a comprehensive review of phase 3 candidates. npj Vaccines.;6(1):17.doi:org/10.1038/s41541-021-00292-w 
17. Wrapp D, Wang N, Corbett KS, Goldsmith JA, Hsieh CL, Abiona O, Graham BS, McLellan JS (2020) Cryo-EM structure of the 2019-nCoV spike in the prefusion conformation. Science 367:1260-1263. https://doi.org/10.1126/science.abb2507

18. Varadwaj PR, Varadwaj A, Marques HM, Yamashita K (2019) Significance of hydrogen bonding and other noncovalent interactions in determining octahedral tilting in the $\mathrm{CH} 3 \mathrm{NH} 3 \mathrm{Pbl} 3$ hybrid organicinorganic halide perovskite solar cell semiconductor. Sci Rep 9:50. https://doi.org/10.1038/s41598018-36218-1

19. Lee $P, W u X(2015)$ Review: modifications of human serum albumin and their binding effect. Curr Pharm Des 21:1862-1865. https://doi.org/10.2174/1381612821666150302115025

20. Jena AB, Kanungo N, Nayak V, Chainy GBN, Dandapat J (2021) Catechin and curcumin interact with $S$ protein of SARS-CoV2 and ACE2 of human cell membrane: insights from computational studies. Sci Rep 11:2043. https://doi.org/10.1038/s41598-021-81462-7

21. Jena AB, Samal RR, Kumari K, Pradhan J, Chainy GB, Subudhi U, Pal S, Dandapat J (2021) The benzene metabolite p-benzoquinone inhibits the catalytic activity of bovine liver catalase: $A$ biophysical study. Int J Biol Macromol. 167:871-880. https://doi.org/10.1016/j.ijbiomac.2020.11.044

22. Sprinzak E, Sattath S, Margalit H (2003) How reliable are experimental protein-protein interaction data?. J Mol Biol 327:919-923. https://doi.org/10.1016/s0022-2836(03)00239-0

23. Daina A, Zoete V (2016) A BOILED-Egg To Predict Gastrointestinal Absorption and Brain Penetration of Small Molecules. Chem Med Chem 11:1117-1121. https://doi.org/10.1002/cmdc.201600182

24. Braun P, Gingras AC (2012) History of protein-protein interactions: from egg-white to complex networks. Proteomics 12:1478-1498. https://doi.org/10.1002/pmic.201100563

25. Lounkine E, Keiser MJ, Whitebread S, Mikhailov D, Hamon J, Jenkins JL, Lavan P, Weber E, Doak AK, Côté S, Shoichet BK (2012) Large-scale prediction and testing of drug activity on side-effect targets. Nature 486:361-367. https://doi.org/10.1038/nature11159

26. Keiser MJ, Setola V, Irwin JJ, Laggner C, Abbas Al, Hufeisen SJ, Jensen NH, Kuijer MB, Matos RC, Tran TB, Whaley R (2009) Predicting new molecular targets for known drugs. Nature 462:175-181. https://doi.org/10.1038/nature08506

27. Gfeller D, Grosdidier A, Wirth M, Daina A, Michielin O, Zoete V (2014) Swiss Target Prediction: a web server for target prediction of bioactive small molecules. Nucleic Acids Res 42:32-38. https://doi.org/10.1093/nar/gku293

28. Oprea TI, Bauman JE, Bologa CG, Buranda T, Chigaev A, Edwards BS, Jarvik JW, Gresham HD, Haynes MK, Hjelle B, Hromas R (2011) Drug Repurposing from an Academic Perspective. Drug Discov Today Ther Strateg 8:61-69. https://doi.org/10.1016/j.ddstr.2011.10.002

29. Kola I, Landis J (2004) Can the pharmaceutical industry reduce attrition rates? Nat Rev Drug Discov 3:711-715. https://doi.org/10.1038/nrd1470

\section{Tables}


Table-1: The binding energy, Interaction type and amino acid involved in interaction of S Protein ACE2 of 2019nCoV and HSA with 2 Phenoxyethanol and Imidazoquinolinone. 


\begin{tabular}{|c|c|c|c|c|}
\hline in- Ligand & $\begin{array}{l}\text { Protein- Ligand } \\
\text { 2D Interaction }\end{array}$ & $\begin{array}{l}\text { Binding } \\
\text { Affinity } \\
(\mathrm{Kcal} / \mathrm{mol})\end{array}$ & Interaction & AA: Name; AA: Chain; AA: No \\
\hline \multirow[t]{4}{*}{$\begin{array}{l}\text { tein - 2- } \\
\text { )xyethanol }\end{array}$} & \multirow[t]{4}{*}{ 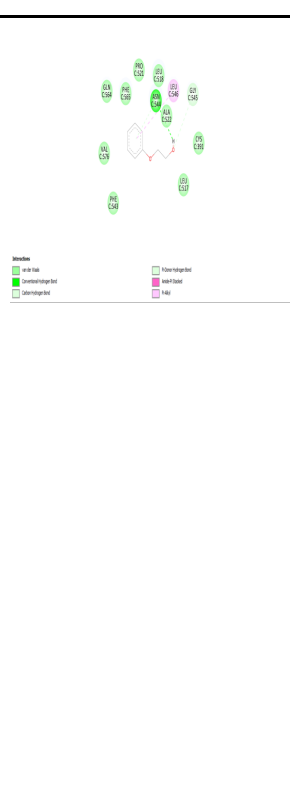 } & \multirow[t]{4}{*}{-5.2} & Vanderwaal & $\begin{array}{l}\text { Gln564, Phe565, Val576, Phe543, } \\
\text { Leu517, Cys391, Ala522, Leu518, } \\
\text { Pro521 }\end{array}$ \\
\hline & & & $\begin{array}{l}\text { Carbon } \\
\text { hydrogen } \\
\text { bond, } \\
\text { Pi donor } \\
\text { hydrogen } \\
\text { bond }\end{array}$ & Gly545 \\
\hline & & & $\begin{array}{l}\text { Conventional } \\
\text { hydrogen } \\
\text { bond }\end{array}$ & Asn544 \\
\hline & & & Pi-alkyl & Leu546 \\
\hline \multirow[t]{5}{*}{$\begin{array}{l}\text { tein - } \\
\text { dazoquinolinone }\end{array}$} & \multirow{5}{*}{$=$} & \multirow[t]{5}{*}{-8.5} & Vanderwaal & $\begin{array}{l}\text { Asn317, Ser316, Thr315, Thr761, } \\
\text { Thr302, Tyr313, Thr768, Gln314, } \\
\text { Asn764, Thr739 }\end{array}$ \\
\hline & & & $\begin{array}{l}\text { Conventional } \\
\text { hydrogen } \\
\text { bond }\end{array}$ & Thr302 \\
\hline & & & Pi-Anion & Asp-737 \\
\hline & & & Pi-alkyl & Cys760, Leu303 \\
\hline & & & Alkyl & $\operatorname{Arg} 765$ \\
\hline \multirow[t]{5}{*}{-2-Phenoxyethanol } & \multirow{5}{*}{${ }_{0}^{2}$} & \multirow[t]{5}{*}{-5.3} & Vanderwaal & $\begin{array}{l}\text { Leu91, } \\
\text { Asn210,Lys562,Ala396, Glu564 }\end{array}$ \\
\hline & & & $\begin{array}{l}\text { Carbon } \\
\text { hydrogen } \\
\text { bond }\end{array}$ & Pro565 \\
\hline & & & Pi-alkyl & Val212,Val209 \\
\hline & & & Pi-sigma & Leu95 \\
\hline & & & $\begin{array}{l}\text { Unfavourable } \\
\text { donor donor }\end{array}$ & $\operatorname{Trp566}$ \\
\hline \multirow[t]{2}{*}{ - Imidazoquinolinone } & & \multirow[t]{2}{*}{-8.5} & Vanderwaal & $\begin{array}{l}\text { Ala348,Thr347, Glu402, } \\
\text { His401,Trp69 }\end{array}$ \\
\hline & & & $\begin{array}{l}\text { Conventional } \\
\text { hydrogen } \\
\text { bond }\end{array}$ & Tyr385 \\
\hline
\end{tabular}

Page 12/17 


\begin{tabular}{|c|c|c|c|c|}
\hline & $a^{3} b^{3}$ & & Pi-alkyl & Arg393 \\
\hline & $*$ & & Pi-Pi stacked & Phe390,Phe40 \\
\hline & \pm & & $\begin{array}{l}\text { Pi-Pi T- } \\
\text { shaped }\end{array}$ & His378 \\
\hline & & & Salt bridge & Asp350, Asp382 \\
\hline \multirow[t]{4}{*}{ 2-Phenoxyethanol } & & \multirow[t]{4}{*}{$\begin{array}{l}-5.3 \\
\text { (IIIA) }\end{array}$} & Vanderwaal & $\begin{array}{l}\text { Asn391,Ala449, Leu387, Val433, } \\
\text { Phe403, Tyr411 }\end{array}$ \\
\hline & & & $\begin{array}{l}\text { Conventional } \\
\text { hydrogen } \\
\text { bond }\end{array}$ & Cys392, Ile388 \\
\hline & & & Pi-sigma & Leu453 \\
\hline & & & Pi-alkyl & Leu430, Leu407 \\
\hline \multirow[t]{5}{*}{ Imidazoquinolinone } & \multirow{5}{*}{$=$} & \multirow[t]{5}{*}{$\begin{array}{l}-9.1 \\
(\mathrm{IB})\end{array}$} & Vander waal & $\begin{array}{l}\text { Met123, Phe134,Glu141, Tyr138, } \\
\text { Phe157, Gly189, His146, Leu115 }\end{array}$ \\
\hline & & & $\begin{array}{l}\text { Conventional } \\
\text { hydrogen } \\
\text { bond }\end{array}$ & Tyr161, Leu185 \\
\hline & & & Pi-sigma & Ile142 \\
\hline & & & Pi-alkyl & Arg186,Lys190 \\
\hline & & & Alkyl & Lys137 \\
\hline
\end{tabular}

Table-2: Protein-Protein interaction depicting 5 lowest binding energy for S Protein- ACE2 complex in the presence or absence of Covaxin adjuvent. 


\begin{tabular}{|c|c|c|c|}
\hline Macromolecule & Binding Positions & $\begin{array}{l}\text { Lowest Energy } \\
\qquad(\mathrm{kJ} / \mathrm{mol})\end{array}$ & $\begin{array}{c}\text { Average } \\
\text { Lowest Energy } \\
(\mathrm{kJ} / \mathrm{mol})\end{array}$ \\
\hline S Protein- ACE2 & 1 & -928.9 & \multirow{5}{*}{-901.2} \\
\hline S Protein- ACE2 & 2 & -923 & \\
\hline S Protein- ACE2 & 3 & -902.4 & \\
\hline S Protein- ACE2 & 4 & -853.3 & \\
\hline S Protein- ACE2 & 5 & -898.4 & \\
\hline S Protein with 2-Phenoxyethanol- ACE2 & 1 & -733.2 & \multirow{5}{*}{-696.64} \\
\hline S Protein with 2-Phenoxyethanol - ACE2 & 2 & -721 & \\
\hline S Protein with 2-Phenoxyethanol - ACE2 & 3 & -701 & \\
\hline S Protein with 2-Phenoxyethanol - ACE2 & 4 & -674 & \\
\hline S Protein with 2-Phenoxyethanol - ACE2 & 5 & -654 & \\
\hline S Protein with imidazoquinolinone - ACE2 & 1 & -630.9 & \multirow{5}{*}{-589.46} \\
\hline S Protein with imidazoquinolinone - ACE2 & 2 & -605.6 & \\
\hline S Protein with imidazoquinolinone - ACE2 & 3 & -567.8 & \\
\hline S Protein with imidazoquinolinone - ACE2 & 4 & -544.1 & \\
\hline S Protein with imidazoquinolinone - ACE2 & 5 & -598.9 & \\
\hline
\end{tabular}

\section{Figures}

\section{Figure 1}

Docked pose of 2-phenoxyethanol in the binding pocket of ACE2. This figure was produced using Discovery Studio Visualizer (http://accelrys.com/products/collaborative-science/biovia-discoverystudio/ visualization-download.php). 


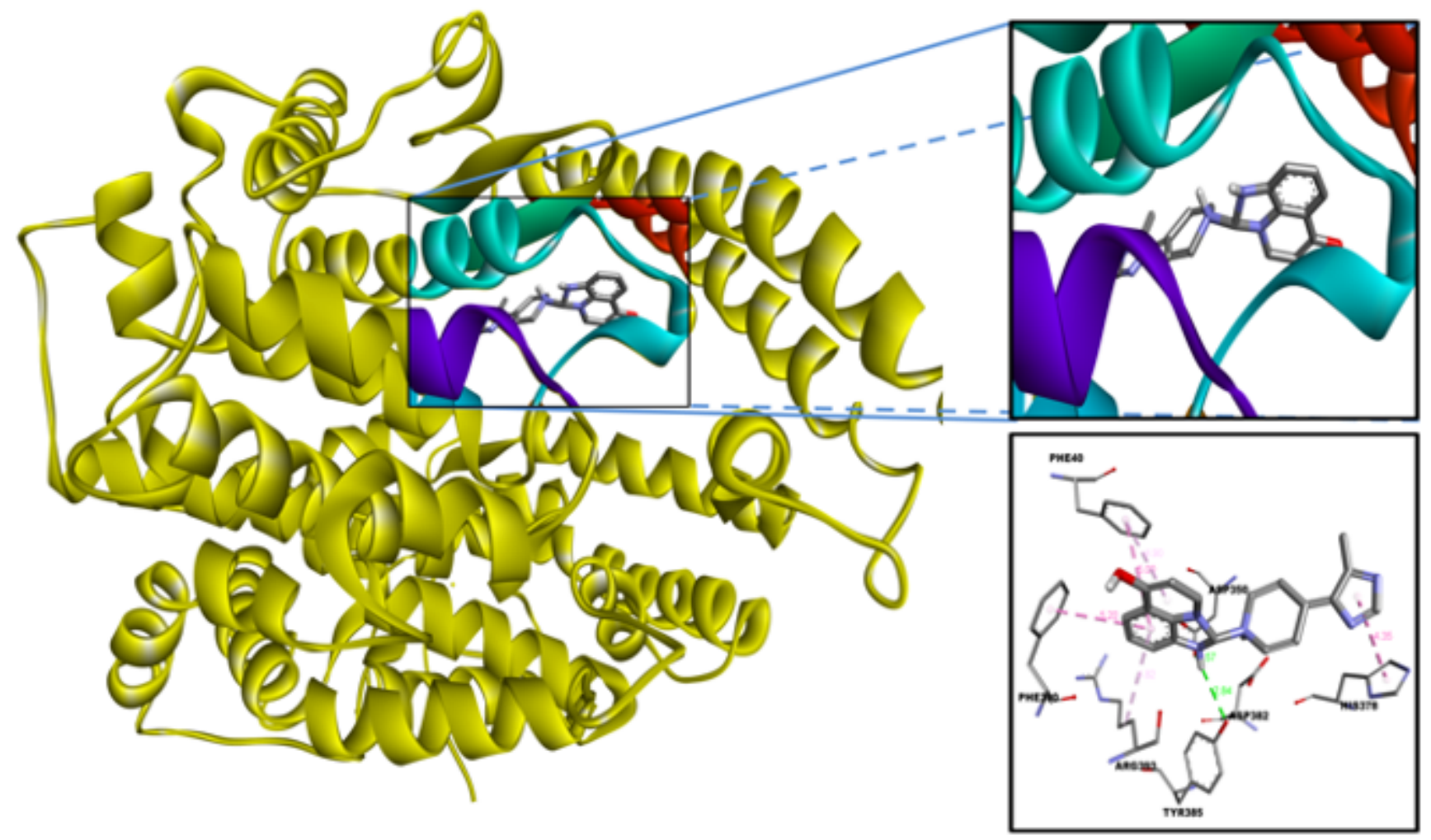

Figure 2

Imidazoquinolinone docked in the binding pocket of ACE2. Discovery Studio Visualizer was used to create this figure. (http://accelrys.com/products/collaborative-science/biovia-discoverystudio/ visualization-download.php). 


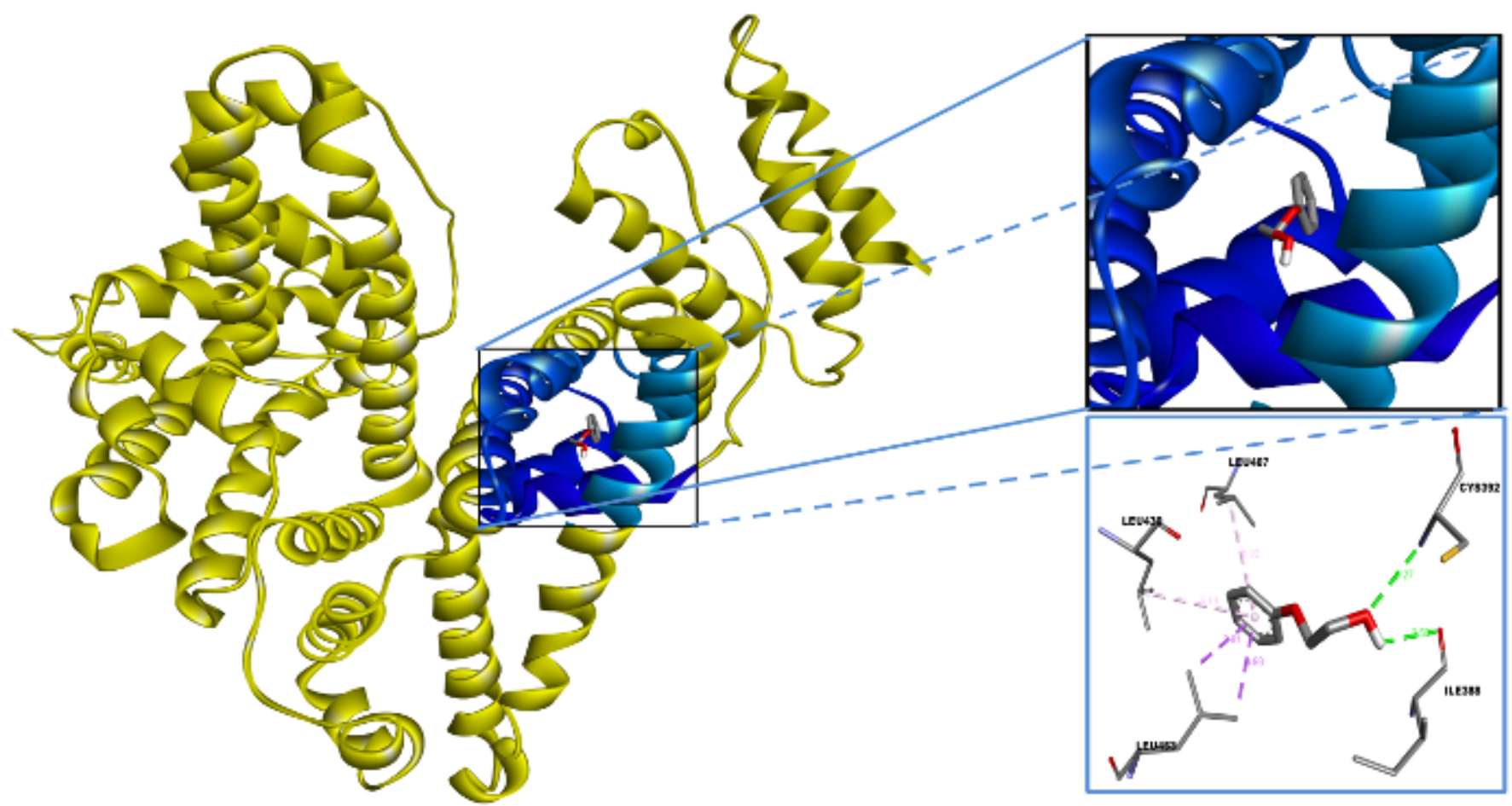

Figure 3

2-phenoxyethanol docked in HSA's binding bag. Discovery Studio Visualizer was used to create this figure. (http://accelrys.com/products/collaborative-science/biovia-discovery-studio/ visualizationdownload.php).

Figure 4

Imidazoquinolinone in a docked position in HSA's binding pocket. This figure was produced using Discovery Studio Visualizer (http://accelrys.com/products/collaborative-science/biovia-discoverystudio/ visualization-download.php).

Figure 5

2- phenoxyethanol docked in the binding pocket of S protein. Discovery studio visualizer was used to build this diagram. (http://accelrys.com/products/collaborative-science/biovia-discoverystudio/ visualization-download.php). 
Figure 6

In the binding pocket of S protein, Imidazoquinolinone is docked. Discovery Studio visualizer was used to build this figure. (http://accelrys.com/products/collaborative-science/biovia-discoverystudio/ visualization-download.php).

Figure 7

In the absence of Covaxin-adjuvant, a docked model depicting S protein interaction with the ACE2 receptor.

Figure 8

Docked model depicting interaction of S Protein with ACE2 receptor in the presence of 2-phenoxyethanol.

Figure 9

In the presence of Imidazoquinolinone, the docked model depicts S Protein's interaction with the ACE2 receptor is shown.

\section{Supplementary Files}

This is a list of supplementary files associated with this preprint. Click to download.

- GraphicalAbstract.png

- SupplTable1.docx

- SupplTable2.png

- supplfigslegends.docx

- SupplFigure1.png

- SupplFigure2.png

- SupplFigure3.png

- SupplFigure4.png 